\title{
Instability and its relation to precipitation over the Eastern Iberian Peninsula
}

\author{
I. Iturrioz ${ }^{1}$, E. Hernández ${ }^{1}$, P. Ribera ${ }^{2}$, and S. Queralt ${ }^{1}$ \\ ${ }^{1}$ Departamento de Física de la Tierra II, Fac. C.C. Físicas, Universidad Complutense de Madrid, 28040, Ciudad Universitaria, \\ Madrid, Spain \\ ${ }^{2}$ Universidad Pablo de Olavide, Sevilla, Spain
}

Received: 12 July 2006 - Revised: 18 January 2007 - Accepted: 31 January 2007 - Published: 26 April 2007

\begin{abstract}
Synoptic situations producing rainfall at four rawinsonde observatories at eastern Spain are classified as stratiform or convective depending on dynamic and thermodynamic instability indices. Two daily radiosonde and daily-accumulated precipitation data from four observatories in Eastern Spain are used: Madrid-Barajas (MB), Murcia (MU), Palma de Mallorca (PA) and Zaragoza (ZA). We calculated two thermodynamic instability indices from radiosonde data: CAPE and LI. Likewise, from ERA40 reanalysis data we have calculated the $\boldsymbol{Q}$ vector divergence over the Iberian Peninsula and Balearic Islands, as a parameter describing dynamical instability. Synoptic situations producing rainfall were classified as convective or stratiform, satisfying a criterion based on the values of dynamic and thermodynamic indices at each observatory. It is observed that the number of days with stratiform precipitation related to the total number of precipitation days follows a consistent annual pattern.
\end{abstract}

\section{Introduction}

Clouds are formed as air parcels are forced to rise, cool and condense. This forcing can be accomplished in several ways including surface heating, frontal lifting, or mixing of the air. In warm clouds, droplets can grow by condensation in a supersaturated environment and by colliding and coalescing with other cloud droplets. Cloud droplets can also form with the aid of cloud condensation nuclei in an unsaturated environment. Warm cloud $\left(T>0^{\circ} \mathrm{C}\right)$ droplets grow and form precipitation also by the collision-coalescence process. In cold clouds $\left(T<0^{\circ} \mathrm{C}\right)$, precipitation forms by deposition, riming, and aggregation. The growth of ice crystals, first by deposition from the vapour phase in mixed clouds, and then by rim-

Correspondence to: I. Iturrioz

(iturrioz@fis.ucm.es) ing and/or aggregation can produce precipitation-sized particles in reasonable periods of time. Precipitation sized particles actually start falling once gravity overcomes the upward vertical movements of the drops in the cloud sustaining them. These upward vertical movements are critical to form precipitation. The ability that the atmosphere has to generate these vertical motions is called atmospheric instability.

Over the Iberian Peninsula very notable differences in the behaviour of precipitation patterns exist. The western and eastern zones are characterized by different precipitation patterns (Brooks et al., 2003). Besides, among the observatories considered in this work, there are differences regarding their precipitation pattern. A separation between the observatories of Madrid and Zaragoza, on one hand, and those of Palma de Mallorca and Murcia, on the other, can be made. Madrid and Zaragoza are characterized fundamentally by notable stratiform precipitation type predominance. Its origin is located mainly in Atlantic depressions with associated frontal systems sweeping the peninsular territory, producing continuous precipitation of stratiform type. This situation is typical during winter months. Precipitation over Eastern Spain observatories (Palma de Mallorca and Murcia) is mostly accumulated on a single season (autumn), when the sea has reached high temperature due to summer warming. Intense showers of convective type dominate, originated by the entrance of hot and humid air into the Iberian Peninsula and by a presence of cold air at higher levels (Dai, 1999; Eshel et al., 2001; Correoso et al., 2005). Hot and humid air at low levels, when entering the Iberian Peninsula is forced to rise to higher levels forced by the orography and afterwards, further uplift is enhanced by the presence of cold air at those high levels. This mechanism is responsible for the formation of thick cumulonimbus, which trigger violent precipitation events. There are notable differences among precipitation types in the different areas of the region studied, represented by the four selected observatories. 


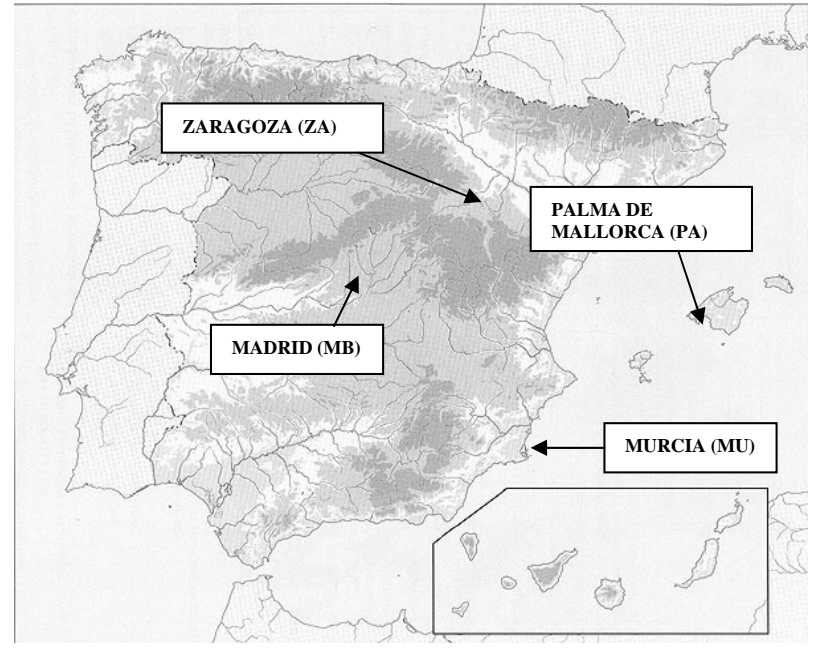

Fig. 1. Orography and the location of the four observatories: Madrid-Barajas (MB), Murcia (MU), Palma de Mallorca (PA) and Zaragoza (ZA).

Rainfall is classified generally in two types, stratiform and convective. This classification is useful, though the distinction between one type and the other is not always as clear and evident as we would like. This is the reason why a great diversity of criteria exists. For example, Houze (1993) considers that stratiform rainfall is accumulated when air vertical motions are small compared with the downward speed of crystal ice and snow (particles of ice in high levels of the cloud play an important role in the process of generation of rainfall). For the case of the convective rainfall, air vertical movements are faster or equal to those of the crystals. The available time observed for the growth of the particles of rainfall is limited, in this case; greatly shorter for the case of the stratified rain. The only fast enough microphysical mechanism of growth that allows the particles to develop rapidly is the liquid water accretion. Nevertheless, the accretion of liquid water plays a role of minor importance in the stratiform precipitation, where the dominant microphysical mechanisms are the deposition of water vapour and the aggregation of ice particles.

On the other hand, Rogers (1989) establishes the classification of rainfall depending on the dominant mechanism responsible for the vertical movements:

- Stratiform precipitation (usually produced by nimbostratus), continuous and with a great extension, is associated with large scale upward motion, produced by frontal or topographic elevation, or determined by a great scale horizontal convergence.

- Convective rainfall (usually produced by cumulonimbos), intense and localised, is associated with local cumulus convection in unstable air.
The aim of this paper is to classify stratiform and convective precipitation events at the selected observatories in the Eastern Iberian Peninsula and Balearic Islands. In order to do this, we have rawinsonde data and rainfall at four observatories from the east of the Iberian Peninsula. Additionally, reanalysis data from ERA 40 allow us to separate the days that are thermodynamically unstable from the those dynamically unstable and to classify the rainfall registered at every observatory. Section 2 describes in detail the data used. The methodology is explained in Sect. 3. Section 4 presents our results and a short discussion. Finally, conclusions are presented in Sect. 5.

\section{Data}

Data consist in two daily (00:00 and 12:00 UTC) observations from four rawinsonde observatories over the Eastern Spain. Data have been obtained from the Integrated Global Rawinsonde Archive (IGRA). Additionally, precipitation data for the same observatories: Madrid-Barajas $\left(40.47^{\circ} \mathrm{N}\right.$, $3.58^{\circ} \mathrm{W}$. Period: 1963 to 2003$)$, Murcia $\left(38.00^{\circ} \mathrm{N}, 1.17^{\circ} \mathrm{W}\right.$. Period: 1984 to 2003), Palma de Mallorca $\left(39.55^{\circ} \mathrm{N}\right.$, $2.62^{\circ}$ E. Period: 1963 to 2002 ) and Zaragoza Airport $\left(41.67^{\circ} \mathrm{N}, 1.02^{\circ} \mathrm{W}\right.$. Period: 1958 to 2003$)$ have been used. The location of the observatories is presented in Fig. 1.

We have calculated several indices of thermodynamic instability, like CAPE and LI. In order to obtain dynamic indices, ERA40 reanalysis data have been used. The selected fields are geopotential height and temperature at $500 \mathrm{hPa}$ and $850 \mathrm{hPa}$. From these parameters we have calculated the divergence of $\boldsymbol{Q}$ vector on a grid comprised between $20^{\circ} \mathrm{N}$ to $70^{\circ} \mathrm{N}$ and $25^{\circ} \mathrm{W}$ to $25^{\circ} \mathrm{E}$, with a grid resolution of $0.5^{\circ}$.

\section{Methodology}

In order to characterize the dynamic instability, the divergence of $\boldsymbol{Q}$ vector at 500 and $850 \mathrm{hPa}$ at each observatory has been calculated (Jusem and Atlas, 1997). Dynamic instability is characterized by negative values of the divergence, while stability is characterized by positive values. The mathematical expression of $\boldsymbol{Q}$ vector is:

$$
\begin{aligned}
& \boldsymbol{Q}_{x}=-\frac{R}{p} \frac{\partial \bar{v}_{g}}{\partial x} \cdot \nabla T \\
& \boldsymbol{Q}_{y}=-\frac{R}{p} \frac{\partial \bar{v}_{g}}{\partial y} \cdot \nabla T
\end{aligned}
$$

where $R$ is the Ideal Gas Constant for dry air, $p$ the corresponding pressure level, $\bar{v}_{g}$ is the geostrophic wind speed vector and $T$ the temperature at that level. The finite difference method has been used to compute the partial differentials. Using this method, we obtain $\boldsymbol{Q}$ divergence. 
Omega equation of the vertical motion can be reduced to an expression that provides us with privileged information. We can compute where vertical motion can develop.

$$
\left(\nabla^{2}+\frac{f^{2}}{\sigma} \frac{\partial^{2}}{\partial p^{2}}\right) \omega=\frac{-2}{\sigma} \nabla \cdot \boldsymbol{Q}
$$

$\omega$ is the isobaric vertical speed, $\omega=\frac{d p}{d t}$

$\sigma$ is the stability parameter, that is defined as follows: $\sigma=-\frac{\alpha}{\theta} \frac{\partial \theta}{\partial p}$, where $\alpha$ is the specific volume and $\theta$ the potential temperature.

The first term of (3) is proportional to $-r \omega$. In such a way, if there is convergence in a level, $\omega$ has to be smaller than zero; that is, the air is moving upwards (instability). On the contrary, if divergence is present, the air has to move downwards because $\omega$ is greater than zero.

Calculating the divergence of $\mathrm{Q}$ in the levels of 500 and 850 for each station, we directly characterize the dynamic instability. For negative divergence there is instability and for positive divergence there is stability.

As we said, in order to characterize thermodynamic stability, several indices have been calculated: CAPE (Convective Available Potential Energy), LI (Lifted Index), TT (Total Totals Index), KI (K Index), SI (Showalter Index) and CIN (Convective INhibition) (De Rubertis, 2005). They provided some redundant information and finally only two of these indices, the ones providing best information, have been included in this paper. CAPE is the abbreviation for Convective Available Potential Energy. CAPE represents the amount of buoyant energy available to accelerate a parcel vertically, or the amount of work a parcel does on the environment. CAPE is defined as:

$$
\mathrm{CAPE}=g \int_{\mathrm{LFC}}^{\mathrm{EL}} \frac{T_{v}(z)-\bar{T}_{v}(z)}{\bar{T}_{v}(z)}
$$

where $T_{v}$ is the wet adiabatic virtual temperature profile of the parcel and $\bar{T}_{v}$ is the virtual temperature profile of the environment. EL is the Equilibrium Level and LFC is the Level of Free Convection.

LI (Lifted Index) can be estimated using a Skew-T thermodynamic diagram. The Lifted Index accounts for low level moisture. A negative lifted index indicates the possibility of convection. To compute LI the temperature of the parcel at $500 \mathrm{hPa}$ is subtracted from the environmental temperature at $500 \mathrm{hPa}$.

We note that CAPE is an index that describes the instability in the troposphere and LI only is defined for the level of $500 \mathrm{mb}$. Nevertheless, they have a very high correlation between them. In Table 1 we can see correlation values between the indices we used on the selected observatories (Table 1.1: Madrid-Barajas, Table 1.2: Murcia, Table 1.3: Palma de Mallorca, Table 1.4: Zaragoza). Correlation values are much lower when the other indices are considered.
Table 1. Correlation values between the indices that were tested: : CAPE (Convective Available Potential Energy), LI (Lifted Index), TT (Total Totals Index), KI (K Index), SI (Showalter Index) and CIN (Convective INhibition).

1.1 Madrid-Barajas

\begin{tabular}{lccccc}
\hline \multicolumn{1}{c}{ LI } & TT & KI & SI & CIN \\
\hline CAPE & -0.72 & 0.15 & 0.16 & -0.30 & 0.14 \\
LI & 1 & -0.69 & -0.60 & 0.78 & 0.01 \\
\hline 1.2 Murcia & & & & \\
\hline \multicolumn{7}{c}{ LI } & TT & KI & SI & CIN \\
\hline CAPE & -0.88 & 0.11 & 0.08 & 0.05 & 0.19 \\
LI & 1 & -0.28 & -0.23 & 0.53 & -0.16 \\
\hline 1.3 Palma de Mallorca & & & \\
\hline \multicolumn{7}{c}{ LI } & TT & KI & SI & CIN \\
\hline CAPE & -0.91 & 0.05 & 0.19 & -0.19 & 0.22 \\
LI & 1 & -0.50 & -0.51 & 0.65 & -0.22 \\
\hline 1.4 Zaragoza & & & & \\
\hline \multicolumn{7}{c}{ LI } & TT & KI & SI & CIN \\
\hline CAPE & 0.90 & 0.08 & 0.08 & -0.11 & 0.03 \\
LI & 1 & -0.66 & -0.62 & 0.76 & -0.25 \\
\hline
\end{tabular}

Adding up, we have an assembly of stations in the Iberian Peninsula and Balearic Islands, each of them being characterized by several dynamic and thermodynamic indices every day and during several years. Within each day, we have rawinsonde data at different hours, so we selected the data of the reanalysis attending to the corresponding sounding. Also we have daily accumulated precipitation data. Our aim is to separate between stratiform and convective precipitation after instability is computed.

To classify the daily type of instability we have considered several criteria (see Appendix for further details). Finally, criterion 1A (see Table 2) was selected because considering the results obtained from the different proposed criteria, it exhibited the most realistic results. In order to compare between results obtained on the four observatories, a method based on percentile analysis was used.

\subsection{Separation between stratiform and convective precipi-} tation

Convective and stratiform precipitation has been classified according to thermodynamic and dynamic indices. The three criteria used to produce this classification are:

First, those days characterized by dynamic instability are selected without considering thermodynamic indices. Precipitation for these days when the value of the dynamic instability index exceeds the percentile 95 (among all the days 
Table 2. Instability criterion. Dynamic instability is based on 95 percentile Q vector divergence at two levels ( 850 and $500 \mathrm{mb}$ ). When Div Q is over 95 percentile at both levels, we consider dynamic instability. TI is the thermodynamic instability index in use. It can be LI or CAPE. We consider the situation is thermodynamically unstable when $\boldsymbol{Q}$ vector divergence is below 95 percentile at least in one of the pressure levels and CAPE or LI (it depends on the criterion used) is over 90 percentile.

\begin{tabular}{ll}
\hline \multicolumn{2}{l}{ INSTABILITY CRITERION $1 \mathrm{~A}$} \\
\hline DYNAMIC INSTABILITY & $\begin{array}{l}\text { DivQ en } 500 \mathrm{hPa} \text {. and DivQ en } 850 \mathrm{hPa} . \\
\text { are both over } 95 \%\end{array}$ \\
\hline THERMODYNAMIC IN- & $\begin{array}{l}\text { DivQ en } 500 \mathrm{hPa} \text { and/or DivQ en } \\
850 \mathrm{hPa} \text { are/is below } 95 \% \text { and TI is over } \\
\text { STABILITY }\end{array}$ \\
& $90 \%$ \\
\hline
\end{tabular}

Stratiform precipitation

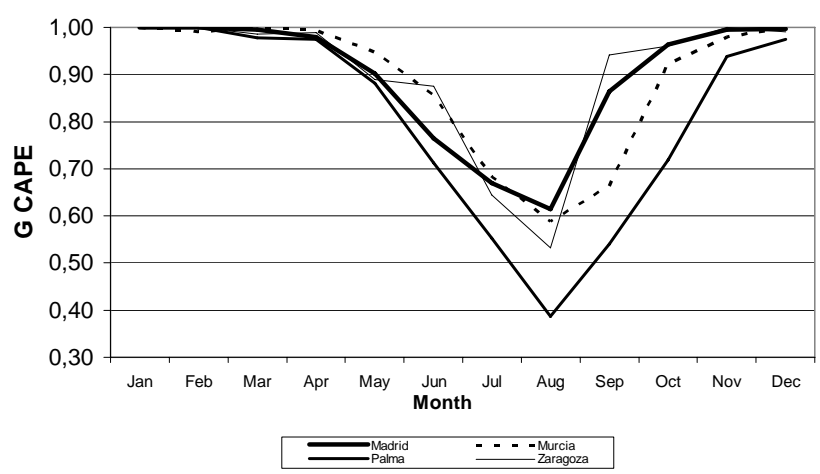

Fig. 2. Number of days with stratiform precipitation over the total number of precipitating days $(G)$ for the whole year in all the observatories, using CAPE as thermodynamic instability index. For the separation between dynamic and thermodynamic instability days, the criteria of Table 2 have been used.

with precipitation at the selected observatory) is classified as stratiform.

Second, when no dynamic instability is present, precipitation will be classified as convective only if the selected thermodynamic index is high enough (higher than $90 \%$ of all the days with precipitation at the selected observatory not previously classified as stratiform).

Third, all the remaining precipitation days, not included in any of the previous classifications, will be considered as stratiform, as the values of the thermodynamic instability index do not exceed the present threshold in order to be classified as convective precipitation.

These criteria are summarized and presented in Table 2. Applying these criteria we can compute the number of days with stratiform precipitation over the total number of precipitating days $(G)$ using instability indices. Thus, $G$ could be considered as the sum of the number of the dynamically unstable days and the number of days that could not be classified in the convective category, based on the preset index

\section{Stratiform precipitation}

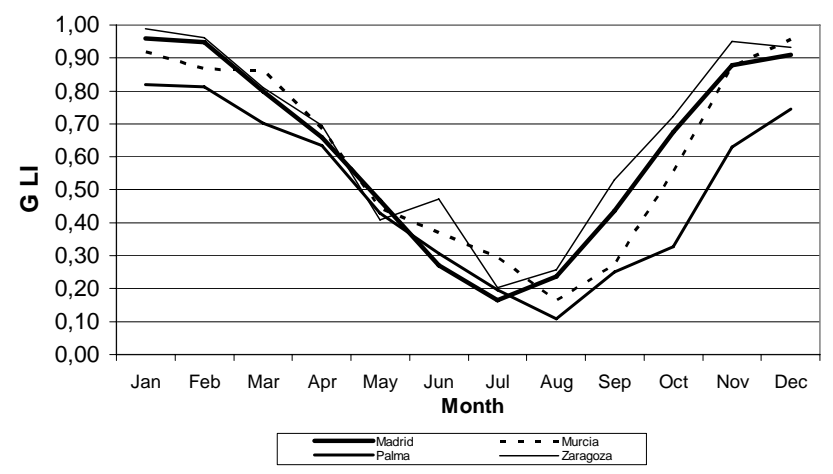

Fig. 3. Number of days with stratiform precipitation over the total number of precipitating days $(G)$ for the whole year at all the observatories, using LI as thermodynamic instability index. For the separation between dynamic and thermodynamic instability days, the criteria of Table 2 have been used.

thresholds. If we define $r$, as the percentage of thermodynamically unstable days that are not dynamically unstable we can calculate $G$ as follows:

$G=s+(1-r)(1-s)$

$G=$ number of days with stratiform precipitation over the total number of precipitating days.

$s=$ Number of dynamically unstable days $\left(I_{D}\right)$ over the total number of days with precipitation $(N)$.

$s=\frac{I_{D}}{N}$

$r=$ Percentage of thermodynamically unstable days using the corresponding thermodynamic index (hereafter, IT) from the $\left(N-I_{D}\right)$ that are not dynamically unstable.

$r=\frac{I_{T}}{N-I_{D}}$ 
Table 3. Number of days with stratiform precipitation over the total number of precipitating days $(G)$ for the whole year in the observatories of Madrid-Barajas (MB), Murcia (MU), Palma de Mallorca (PA) and Zaragoza (ZA). Using CAPE and LI as thermodynamic instability indices, two different results for $G$ were obtained. For the separation between dynamic and thermodynamic instability days, the criteria in Table 1 have been used.

\begin{tabular}{ccccccccc}
\hline & \multicolumn{2}{c}{ MB } & \multicolumn{2}{c}{ MU } & \multicolumn{2}{c}{ PA } & \multicolumn{2}{c}{ ZA } \\
\hline & $G$ CAPE & $G$ LI & $G$ CAPE & $G$ LI & $G$ CAPE & $G$ LI & $G$ CAPE & $G$ LI \\
\hline Jan & 1.00 & 0.96 & 1.00 & 0.92 & 1.00 & 0.82 & 1.00 & 0.99 \\
Feb & 1.00 & 0.95 & 0.99 & 0.87 & 1.00 & 0.81 & 1.00 & 0.96 \\
March & 1.00 & 0.80 & 1.00 & 0.86 & 0.98 & 0.70 & 0.99 & 0.81 \\
April & 0.98 & 0.66 & 0.99 & 0.68 & 0.97 & 0.64 & 0.99 & 0.70 \\
May & 0.90 & 0.47 & 0.95 & 0.44 & 0.88 & 0.43 & 0.89 & 0.41 \\
June & 0.77 & 0.27 & 0.85 & 0.37 & 0.71 & 0.31 & 0.88 & 0.47 \\
July & 0.67 & 0.17 & 0.68 & 0.30 & 0.55 & 0.20 & 0.64 & 0.20 \\
Aug & 0.61 & 0.24 & 0.59 & 0.16 & 0.39 & 0.11 & 0.53 & 0.26 \\
Sep & 0.86 & 0.44 & 0.66 & 0.27 & 0.54 & 0.25 & 0.94 & 0.53 \\
Oct & 0.96 & 0.67 & 0.92 & 0.55 & 0.72 & 0.33 & 0.96 & 0.72 \\
Nov & 1.00 & 0.88 & 0.98 & 0.87 & 0.94 & 0.63 & 1.00 & 0.95 \\
Dec & 1.00 & 0.91 & 1.00 & 0.96 & 0.97 & 0.74 & 0.99 & 0.93 \\
\hline
\end{tabular}

\section{Results and discussion}

Figures 2 and 3 and Table 3 describe the evolution of mean monthly values for $G$ (see Eq. 5) based on the two thermodynamic indices (CAPE and LI). $G$ values have been calculated once per day, at 12:00 UTC and averaged for each month. The evolution of $G$ values was computed for each observatory. An instability criterion (Table 2) has been applied and by using the two indices, CAPE and LI, two different results are presented: " $G$ CAPE" (Fig. 2) and " $G$ LI" (Fig. 3).

The instability criterion showed that most winter precipitation events can be classified as stratiform for all the observatories as, in some way, was expected. Nevertheless, the greatest discrepancy is observed when we focus our attention on summer precipitation. For this season, G CAPE decreases significantly at all observatories (Fig. 2). Figure 3 and Table 3 show that G LI decreases below 20\% during summer months. This annual distribution of precipitation pattern using LI index in the instability criterion is in agreement with the results of previous studies (Tremblay, 2005), i.e., the amount of stratiform precipitation is greater in winter than in summer. Also, convective events are more likely in August, September and October (Correoso et al., 2005). Our results show that CAPE overestimates the amount of precipitation collected in summer (see for example the values in Table 3 for Palma de Mallorca observatory in June). A value of $71 \%$ for the stratiform precipitation amount is considered too high. Much more realistic results were obtained from LI, with a value of $31 \%$.

It is worth pointing out that the proposed method classifies precipitation types in a realistic way in the different observatories throughout the year. Results show an increase in the percentage of stratiform precipitation during winter months and a decrease in summer. Also, it was found that convective events are more probable to occur at seaside observatories than at inland observatories in Madrid and Zaragoza (Fig. 3).

\section{Conclusions}

Precipitation at four meteorological observatories in Spain has been classified as stratiform or convective following an easily implemented methodology based on the use of stability indices. This method allows the generation of an annual pattern for precipitation. When the patterns obtained were analyzed, results were in very good agreement with previous publications and common experience, both regarding the type and frequency of different precipitation events. Summer rainfall is predominantly convective, while winter precipitation is mostly stratiform.

The comparison between results obtained using CAPE or LI indices shows a better performance when using LI, which reproduces better the quantity of convective rainfall impounded during September and October. Murcia and Palma (seaside observatories) have a more intense convective behaviour than Madrid and Zaragoza (inland observatories), especially during August, September and October.

\section{Appendix A Instability criteria}

All instability criteria are based on the fact that the dynamic instability dominates over the thermodynamic one. So, first of all, we compute dynamic instability at two levels of 500 and $850 \mathrm{hPa}$. The criteria are the following: 


\begin{tabular}{|c|c|c|}
\hline \multicolumn{3}{|c|}{ INSTABILITY CRITERION 1} \\
\hline & CRITERION 1A & CRITERION 1B \\
\hline $\begin{array}{l}\text { DYNAMIC } \\
\text { INSTABILITY }\end{array}$ & \multicolumn{2}{|c|}{$\begin{array}{l}\text { DivQ en } 500 \mathrm{hPa} \text {. and DivQ en } 850 \mathrm{hPa} \text {. } \\
\text { are both over } 95 \%\end{array}$} \\
\hline $\begin{array}{l}\text { THERMO- } \\
\text { DYNAMIC } \\
\text { INSTABILITY }\end{array}$ & $\begin{array}{l}\text { DivQ en } 500 \mathrm{hPa} \text {. } \\
\text { and/or DivQ en } \\
850 \mathrm{hPa} \text {. are/is } \\
\text { below } 95 \% \text { and } \mathrm{TI} \\
\text { is over } 90 \%\end{array}$ & $\begin{array}{l}\text { DivQ en } 500 \mathrm{hPa} \text {. } \\
\text { and/or DivQ en } \\
850 \mathrm{hPa} \text {. are/is } \\
\text { below } 95 \% \text { and TI } \\
\text { is over } 95 \%\end{array}$ \\
\hline
\end{tabular}

\begin{tabular}{|c|c|c|}
\hline \multicolumn{3}{|c|}{ INSTABILITY CRITERION 2} \\
\hline & CRITERION 2A & CRITERION 2B \\
\hline $\begin{array}{l}\text { DYNAMIC } \\
\text { INSTABILITY }\end{array}$ & \multicolumn{2}{|c|}{$\begin{array}{l}\text { DivQ en } 500 \mathrm{hPa} \text {. and DivQ en } 850 \mathrm{hPa} \text {. } \\
\text { are both over } 90 \%\end{array}$} \\
\hline $\begin{array}{l}\text { THERMO- } \\
\text { DYNAMIC } \\
\text { INSTABILITY }\end{array}$ & $\begin{array}{l}\text { DivQ en } 500 \mathrm{hPa} \text {. } \\
\text { and/or DivQ en } \\
850 \mathrm{hPa} \text {. are/is } \\
\text { below } 90 \% \text { and TI } \\
\text { is over } 90 \%\end{array}$ & $\begin{array}{l}\text { DivQ en } 500 \mathrm{hPa} \text {. } \\
\text { and/or DivQ en } \\
850 \mathrm{hPa} \text {. are/is } \\
\text { below } 90 \% \text { and } \mathrm{TI} \\
\text { is over } 95 \%\end{array}$ \\
\hline
\end{tabular}

\begin{tabular}{lll}
\hline \multicolumn{3}{c}{ INSTABILITY CRITERION 3 } \\
\hline & CRITERION 3A & \multicolumn{1}{c}{ CRITERION 3B } \\
\hline $\begin{array}{l}\text { DYNAMIC } \\
\text { INSTABILITY }\end{array}$ & $\begin{array}{l}\text { DivQ en 500 hPa. or DivQ en } 850 \mathrm{hPa} . \\
\text { is over 95\% }\end{array}$ \\
\hline THERMO- & $\begin{array}{l}\text { DivQ en 500 hPa. } \\
\text { and DivQ en }\end{array}$ & $\begin{array}{l}\text { DivQ en 500 hPa. } \\
\text { and DivQ en } \\
\text { DYNAMIC } \\
\text { INSTABILITY }\end{array}$ \\
$\begin{array}{l}\text { 850 hPa. are both } \\
\text { below 95\% and TI } \\
\text { is over 90\% }\end{array}$ & $\begin{array}{l}\text { 850 hPa. are both } \\
\text { below 95\% and TI } \\
\text { is over 95\% }\end{array}$ \\
\hline
\end{tabular}

Acknowledgements. The author wishes to thank the Instituto Nacional de Meteorologia for providing the precipitation data and ECMWF for the reanalysis data. The Ministerio de Educación y Ciencia supported this study through the DINPRE (DINámica de la PREcipitación) project (CGL2004-05187-C03-01/CLI). Comments and suggestions provided by two anonymous reviewers helped to improve the final version of this paper.

Edited by: S. C. Michaelides and E. Amitai

Reviewed by: anonymous referees

\section{References}

Brooks, H., Lee, J., and Craven, J. P.: The Spatial distribution of severe thunderstorm and tornado environments from global reanalysis data, Atmos. Res., 67-68, 73-94, 2003.

Correoso, J. F., Hernández, E., and García Herrera, R.: A 3year study of cloud-toground lightning flash characteristics of Mesoscale convective systems over the Western Mediterranean Sea, Atmos. Res., 79, 89-107, 2005.

Dai, A. G.: Recent changes in the diurnal cycle of precipitation over the United States, Geophys. Res. Lett., 26, 341-344, 1999.

De Rubertis, D.: Recent Trends in four common stability Indices derived from U.S. Radiosonde Observations, J. Climate, 19, 309-323, 2005.

Eshel, G. and Farrel, B.: Thermodynamics of Eastern Mediterranean Rainfall Variability, J. Atmos. Sci., 58(1), 87-92, 2001.

Houze, R. A.: Cloud Dynamics, Academic Press, pp. 197-200, 1993.

Jusem, J. C. and Atlas, R.: Diagnostic evaluation of vertical motion forcing mechanisms by using Q-vector partitioning, Mon. Wea. Rev., 126, 2166-2184, 1997.

Rogers, R. R. and Yau, M. K.: A Short Course in Cloud Physics, Pergamon Press, pp. 196-205, 1989.

Tremblay, A.: The Stratiform and Convective Components of Surface Precipitation, J. Atmos. Sci., 62(5), 1513-1528, 2005. 